\title{
Protagonismo negro, educação antirracismo e os quilombolas urbanos como "outros sujeitos": uma problematização necessária
}

Black protagonism, anti-racism education and urban quilombolas as "other subjects": a necessary problematization

\author{
Cassia Engres Mocelin* \\ Patrícia Krieger Grossi**
}

\begin{abstract}
Resumo - Este artigo objetiva discutir a opressão e a segregação dos negros como "outros sujeitos", o protagonismo de suas lutas como pressuposto de um processo político-social-educacional afirmativo e antirracista. Apoia-se no materialismo histórico-dialético como método e no material empírico, coletado nos quilombos urbanos do município de Porto Alegre, cotejando o enfoque educacional. Nesse sentido, os outros sujeitos são sujeitos de direitos e sujeitos que respondem, resistem e reagem a uma cultura hegemônica. Desse modo, não são assujeitados, mas sujeitos da contracultura, das singularidades dentro da universalidade, das diversidades e das diferenças. Assim sendo, é necessário pensar e tomar a educação como processos sociais e práticas afirmativas e antirracistas acerca das populações que foram historicamente oprimidas em sua cultura, condições e modos de vida. Vê-se, pois, uma dialética entre afirmação desses outros sujeitos e repressão e manutenção das formas de dominação e desigualdades sociais.

Palavras-chave: educação antirracismo; lutas sociais; outros sujeitos; quilombos urbanos; sujeito de direitos.
\end{abstract}

\begin{abstract}
This article aims to discuss the oppression and segregation of other subjects and the protagonism of their struggles as a presupposition of an affirmative and anti-racist political-social-educational process. It is based on historical-dialectical materialism as a method and on empirical material collected in urban quilombos of Porto Alegre, Brazil, focusing on the educational approach. In this sense, other subjects are subjects of rights, who respond, resist, and
\end{abstract}

\footnotetext{
* Assistente Social da Universidade Federal de Santa Maria na Pró-Reitoria de Assuntos Estudantis. Mestra em Extensão Rural pela Universidade Federal de Santa Maria e Doutoranda no Programa de Pós-Graduação em Serviço Social da Pontifícia Universidade Católica do Rio Grande do Sul - PUCRS, Bolsista CAPES/PROEX. E-mail: cassiaengres @hotmail.com. ORCID: http://orcid.org/0000-0002-3751-5580.

** Doutora em Serviço Social pela Universidade de Toronto (Canadá). Professora Adjunta da Graduação em Serviço Social e dos Programas de Pós-graduação em Serviço Social e em Gerontologia Biomédica da Pontifícia Universidade Católica do Rio Grande do Sul - PUCRS. Coordenadora do Núcleo de Estudos e Pesquisa em Violência, Ética e Direitos Humanos - NEPEVEDH e do Grupo de Estudos e Pesquisa em Violência - NEPEVI (ambos da PUCRS). Pesquisadora Produtividade em Pesquisa do CNPQ 1C. E-mail: pkgrossi@pucrs.br. ORCID: http://orcid.org/0000-0003-1917-0221.
} 
react to a hegemonic culture. Hence, they are not subjected, but the subjects of counterculture, of singularities within universality, of diversity and of difference. Thus, it is necessary to reflect on and take education as social processes and affirmative, anti-racist practices in relation to the populations that have had their culture, conditions, and ways of life historically oppressed. We see a dialectic relation between the affirmation of these other subjects and both the repression and the maintenance of forms of domination and social inequalities. Keywords: Anti-racism education; social struggles; other subjects; urban quilombos; subjects of rights.

\section{Introdução}

O Brasil forjou-se enquanto Estado-Nação ancorado no latifúndio, na monocultura e no trabalho escravo, inicialmente da população indígena e, posteriormente, da população negra africana. A escravidão foi, portanto, um elemento fundamental no processo de acumulação de capital, tendo o racismo como sua justificativa ideológica. Por isso, as "[...] correntes da escravidão se confundem com as raízes do capitalismo" (SILVA, 2016, p. 27). Não havia direitos para quem não era considerado como ser humano. Tampouco tais populações foram tomadas como sujeitos da história intelectual e cultural do Brasil, assim como em toda a América Latina. Por isso, a cultura e a afirmação de direitos não são noções cristalizadas no imaginário dos/as cidadãos/ãs brasileiros/as. Ou seja, não existe - ou, ainda, existe de forma parcial - a concepção de sujeitos de direitos.

Foi por meio das lutas sociais, expressas na rebeldia e na resistência da classe trabalhadora frente à exploração e expropriação do capital, que a questão social rompeu o domínio privado das relações entre capital e trabalho, extrapolando da esfera privada para a esfera pública. Para lamamoto (2015), a questão social na cena contemporânea e na era das finanças está sendo reconfigurada, tendo em vista o predomínio do capital financeiro.

Nessa perspectiva, a questão social é mais do que as expressões de pobreza, miséria e 'exclusão'. Condensa a banalização do humano, que atesta a radicalidade da alienação e a invisibilidade do trabalho social - e dos sujeitos que o realizam - na era do capital fetiche. A subordinação da sociabilidade humana às coisas - ao capital-dinheiro e ao capital mercadoria -, retrata, na contemporaneidade, um desenvolvimento econômico que se traduz como barbárie social. (IAMAMOTO, 2015, p. 125).

A questão social também condensa uma arena de lutas e disputas políticas entre projetos societários distintos, gerados pelo conjunto das desigualdades sociais, econômicas, políticas e culturais. Essas são "[...] mediatizadas por disparidades nas relações de gênero, características étnico- 


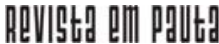

\} PROTAGONISMO NEGRO - MOCELIN, C. E.; GROSSI, P. K. \}

DOI: $10.12957 / R E P .2020 .52058$

raciais e formações regionais, colocando em causa amplos segmentos da sociedade civil no acesso aos bens da civilização" (IAMAMOTO, 2015, p. 160).

Neste artigo, optou-se pela utilização da questão racial, considerando o termo "raça" no seu sentido sociológico, político, e não biológico. Compartilhamos a posição de Eurico (2013) de que a questão racial é ampliada na trama das relações sociais e na forma como a população negra acessa a riqueza socialmente produzida, os bens e serviços, como se insere no mercado de trabalho, na invisibilidade escolar, entre outros aspectos. Nessa perspectiva, consideramos que o racismo é estrutural, pois que ele organiza as relações sociais tanto quanto as relações de classe.

No contexto da América Latina, as populações indígenas, negra, quilombola, os coletivos de mulheres e LGBTI, trabalhadores/as rurais e urbanos/as, por meio de suas lutas sociais, atribuem densidade política à questão social e à questão racial na cena pública. Reside aí a importância de dar visibilidade a esses sujeitos, assim como trazer o protagonismo de suas lutas sociais.

No âmbito do Serviço Social, o Código de Ética, em 1993, por meio de seus princípios fundamentais, ressignifica a questão racial e orienta a categoria profissional ao "Empenho na eliminação de todas as formas de preconceito, incentivando o respeito à diversidade, à participação de grupos socialmente discriminados e à discussão das diferenças" (CFESS, 2012, p. 23-24), assim como articula a construção e "Opção por um projeto profissional vinculado ao processo de construção de uma nova ordem societária, sem dominação, exploração de classe, etnia e gênero" (CFESS, 2012, p. 23-24). Desse modo, a luta contra o racismo é também uma luta contra o capitalismo, em que raça e classe formam um todo indissociável.

Este artigo objetiva discutir a opressão e a segregação dos negros como "outros sujeitos" (ARROYO, 2014) e o protagonismo de suas lutas como pressuposto de um processo político-social-educacional afirmativo e antirracista. Para tanto, procura dialogar com Arroyo (2014) e Mariátegui $(2003,2007)$ no intuito de demonstrar o direito à educação como uma luta social e histórica dos povos considerados pelas elites latino-americanas do capital como sendo "sem cultura". O estudo apoia-se em material empírico, coletado nos quilombos urbanos do município de Porto Alegre, ${ }^{1}$ cotejando o enfoque educacional, bem como no materialismo históricodialético como método. Para este, seu ponto de partida são os sujeitos reais na sua existência empírica, o que possibilita a compreensão da intersecção entre classe, raça e gênero no Brasil.

\footnotetext{
1 Esses dados foram coletados a partir da pesquisa guarda-chuva Mulheres quilombolas e acesso aos direitos de cidadania: desafios para as políticas públicas, que conta com o apoio do CNPq, através do edital MCTIC/CNPq n. 28/ 2018 - Universal/Faixa C (Processo: 434180/2018-1), e da Fapergs, através do Edital 02/2017 - PqG (Processo 17/ 2551-0000)997-5). Projeto aprovado pelo CEP da PUCRS por meio do CAAE. 48852615.5.0000.5336.
} 


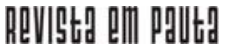

\} PROTAGONISMO NEGRO - MOCELIN, C. E.; GROSSI, P. K. \}

DOI: $10.12957 /$ REP.2020.52058

Nesta perspectiva, a população quilombola apresenta-se como um dos segmentos sociais mais vulnerabilizados, inclusive com indicadores socioeconômicos e educacionais abaixo da população negra em geral. Conforme o Art. $2^{\circ}$ do Decreto ${ }^{\circ}$ 4.887, de 20 de novembro de 2003, consideram-se remanescentes das comunidades quilombolas "[...] os grupos étnico-raciais, segundo critérios de auto-atribuição, com trajetória histórica própria, dotados de relações territoriais específicas, com presunção de ancestralidade negra relacionada com a resistência à opressão histórica sofrida" (BRASIL, 2003a, p. 1).

Embora a maioria das comunidades remanescentes de quilombos esteja localizada no meio rural, também existem quilombos urbanos. O primeiro deles, certificado em 2004, foi o Quilombo da Família Silva, localizado no município de Porto Alegre. Segundo a Fundação Palmares $(2020)^{2}$, existem no Brasil 3.432 comunidades remanescentes de quilombos certificadas, sendo que 136 destas estão no Rio Grande do Sul.

A pesquisa encontra-se em andamento, e a coleta de dados das entrevistas que constam no presente artigo foi realizada em 2018 e 2019. Em Porto Alegre, existem atualmente cinco comunidades quilombolas reconhecidas (Quilombo do Areal, Quilombo dos Alpes, Quilombo Família Silva, Quilombo Família Lemos e Quilombo Fidelix), sendo que todas participaram de nossa pesquisa. Fizeram parte em torno de 30 pessoas (mulheres quilombolas, lideranças quilombolas, idosos quilombolas), em entrevistas e grupos focais entre todos os quilombos, que foram gravados, posteriormente transcritos e submetidos à análise de conteúdo temática.

Para apresentar a pesquisa desenvolvida, o texto está organizado em três partes, além da presente introdução. A primeira discute o processo de opressão e segregação dos quilombolas urbanos como "outros sujeitos" no referente à fruição do direito à educação. A segunda parte busca tensionar a potencialidade da educação como uma práxis antirracista, considerando o protagonismo e as vozes dos "outros sujeitos". Por fim, tem-se as considerações finais.

\section{Lutas sociais e reconhecimento do direito à educação: problematizando os quilombolas urbanos como "outros sujeitos"}

Para Arroyo (2014), há uma história cultural ocultada, e, assim, ocultam-se também seus sujeitos sociais, étnicos, raciais, camponeses e das florestas. Essa história só é desocultada por meio da luta empreendida pelos movimentos sociais e de sua radicalidade política enquanto coletivos

${ }^{2}$ Conforme informações extraídas do sítio da Fundação Palmares, atualizada em 21/02/2020. 


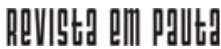

\} PROTAGONISMO NEGRO - MOCELIN, C. E.; GROSSI, P. K. \}

DOI: $10.12957 /$ REP.2020.52058

populares. "Ocultar a cultura popular tem sido uma forma de ocultar o povo como sujeito de cultura" (ARROYO, 2014, p. 109) e da história.

Além disso, o ocultamento e o apagamento não se referem apenas à dimensão cultural e estética, mas também ao entendimento de que aqueles sujeitos apagados culturalmente são oprimidos e segregados social e racialmente. São esses mesmos sujeitos que tiveram suas culturas apagadas e seus modos e condições de vida destroçados quando do descobrimentoencobrimento da América pelos povos ibéricos, e que continuaram, no devir sócio-histórico, como culturas silenciadas e sujeitos oprimidos, funcionalidades à lógica do capital.

No entanto, existe um movimento contra-hegemônico de resistência dos povos oprimidos, dos que vivem à margem e que estão silenciados. Na tentativa de desocultar a história, desocultam-se a si mesmos e, assim, afirmam-se enquanto sujeitos de cultura e sujeitos de direitos, ou seja, "outros sujeitos". Mas quem são "os outros sujeitos"?

Em nossas sociedades latino-americanas são os grupos que se fazem presentes em ações afirmativas nos campos, nas florestas, nas cidades, questionando as políticas públicas, resistindo à segregação, exigindo direitos. Inclusive o direito à escola, à universidade. São os coletivos sociais, de gênero, etnia, raça, camponeses, quilombolas, trabalhadores empobrecidos que se afirmam sujeitos de direitos. Outros sujeitos. (ARROYO, 2014, p. 9 - Grifo nosso).

Arroyo (2014) desenvolve o conceito de "outros sujeitos", a qual será problematizada neste artigo, pois, ao considerar as populações étnicas e raciais como "outros sujeitos", ele evidencia a histórica opressão e segregação que estes grupos vivenciam em uma sociedade capitalista e racista, que os alija de seus direitos de cidadania e nega toda a contribuição de sua cultura para a história. Todavia, esses "outros sujeitos" são protagonistas de lutas sociais e enfrentamentos a este modo de produção. Salientamos que o avanço da luta antirracista não concebe mais essa visão como "não sujeitos", e sim como sujeitos de direitos. Essa é a realidade do movimento negro, do movimento quilombola, do movimento ribeirinho, do movimento camponês, de afirmação da resistência e de libertação frente a reiterados processos opressivos de culturicídios e etnocídios. Portanto, não são assujeitados, mas sim sujeitos da contracultura, das singularidades dentro da universalidade, das diversidades.

Esses processos afirmativos se contrapõem ao mito a-histórico e ao mito da condição de povos bárbaros primitivos e incultos (ARROYO, 2014), fundamentados principalmente nas teorias deterministas, no racismo científico, na hierarquização das raças, no darwinismo social e nas teorias evolucionistas. Contrapõem-se também à cultura hegemônica, única, que conta a história como se a cultura latino-americana tivesse começado com o processo de descobrimento/encobrimento. Nesse sentido, 


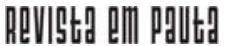

\} PROTAGONISMO NEGRO - MOCELIN, C. E.; GROSSI, P. K. \}

DOI: $10.12957 /$ REP.2020.52058

O movimento negro repõe as culturas afro de todos os coletivos afrodescendentes latino-americanos. A história contada de nossa cultura é etnicista e racista, não apenas porque carrega preconceitos contra essas culturas, mas porque as pensa tão inexistentes, pré-históricas quanto seus povos relegados à inexistência. (ARROYO, 2014, p. 110).

No Brasil, desde o Período Colonial, o Estado sempre permitiu, fomentou e legitimou legislações que dificultaram e proibiram o acesso e a permanência das populações negra e indígena no sistema educacional. Destacam-se o Decreto $n^{\circ} 1.331 / 1854$, que não admitia negros/as na escola, e o Decreto $n^{\circ} 7.031 / 1878$, que só permitia a essa população estudar no período noturno (BRASIL, 1854, 1878).

Além da histórica opressão e segregação socioespacial e socioeducacional que determinou um lugar na divisão social e técnica do trabalho no capitalismo para esse segmento populacional, o princípio do privilégio da educação "[...] persistia por la simple razón de que persistia el privilegio de la riqueza y de la casta" (MARIÁTEGUI, 2007, p. 88). No Brasil, tal privilégio foi fomentado principalmente pela Lei do $\mathrm{Boi}^{3}$.

A defesa do acesso à cultura e à educação a todos os indivíduos não era pauta na realidade dos países latino-americanos, corroborando a segregação de alguns grupos. Assim, "El incipiente desarrollo, el mísero radio de la instrucción pública, cerraban los grados superiores de la enseñanza a las clases pobres" (MARIÁTEGUI, 2007, p. 107).

Por conseguinte, o Brasil foi o último país na América Latina a instituir universidades, que passaram a existir somente no início do século XX. Essas instituições atravessaram seu primeiro século de existência alijando grande parte da população. Caracterizaram e constituíram-se historicamente em espaços elitizados, destinados às classes dominantes do capital econômico, político, social e simbólico.

A atmosfera de redemocratização do país na década de 1980 fortaleceu as pautas em relação à discriminação racial e o estabelecimento de ações afirmativas. Diante disso, o movimento negro e as lideranças das comunidades remanescentes de quilombos passaram a buscar o reconhecimento dos seus direitos de cidadania, assim como a pressionar o Estado por posturas e ações mais ativas em relação às condições de vida da população negra do país.

Na sequência, a Constituição da República de 1988 reconheceu os/as quilombolas como sujeitos de direitos e como membros dos diferentes grupos que formaram a sociedade brasileira. Assegurou-lhes o direito à titulação das terras e à preservação dos seus modos de vida, criações culturais e artísticas, os quais passaram a ser considerados patrimônio cultural.

\footnotetext{
${ }^{3}$ A Cota do Boi, instituída em 1968, perdurou até o governo de José Sarney. Favoreceu e assegurou à elite rural o ingresso em determinados cursos superiores nos estabelecimentos públicos federais. Adotava como critério determinante a origem geográfica rural, reiterando o privilégio da educação associado ao privilégio de renda.
} 


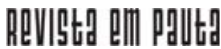

\} PROTAGONISMO NEGRO - MOCELIN, C. E.; GROSSI, P. K. \}

DOI: $10.12957 /$ REP.2020.52058

Posteriormente, o estabelecimento do Programa Nacional de Ações Afirmativas, por meio do Decreto n. 4.228/2002, integrando ações nas áreas de educação, cultura, saúde, trabalho e juventude, materializou o compromisso afirmativo do Estado com a questão racial (BRASIL, 2002). Especificamente na área educacional, destacam-se como desdobramento desse programa a ação afirmativa estabelecida pela Lei $n^{\circ} 10.639 / 2003$, que trata da obrigatoriedade do ensino de história e cultura africana, afrobrasileira e indígena no ensino básico (BRASIL, 2003b), e a ação afirmativa que estabelece o sistema de cotas sociais e étnico-raciais para o acesso ao ensino médio, tecnológico e superior público, por meio da Lei $\mathrm{n}^{\circ} 12.711$ / 2012 (BRASIL, 2012).

Com isso, chega-se ao momento em que a população negra e indígena, depois de um longo processo de lutas sociais, adentra as universidades e instituições técnicas federais em um número cada vez maior. Nesse sentido, uma pesquisa (V PESQUISA, 2019) sobre o perfil dos/as estudantes de graduação das instituições federais de ensino superior do Brasil revelou que, pela primeira vez dentro do espectro temporal das pesquisas já realizadas (1997-2018), o percentual de estudantes negros/as (pretos/as quilombolas, pretos/as não quilombolas) e pardos/as alcança a maioria absoluta do universo pesquisado $-51,2 \%$ dos/as estudantes. Outro dado significativo que a pesquisa apontou acerca do ingresso no ensino superior brasileiro refere-se especificamente aos/às estudantes quilombolas, tendo um aumento de $154 \%$, passando de 4.231 para 10.747 estudantes (V PESQUISA, 2019).

O ingresso crescente desse segmento populacional nos espaços escolares nem sempre é acompanhado pelo reconhecimento de seus membros como sujeitos de direitos, tendo em vista o caráter antipopular e elitista do Estado brasileiro, razão pela qual o exercício da cidadania das classes populares sempre foi restringido (IAMAMOTO, 2015). Nessa mesma perspectiva, Arroyo (2014) diz que as reações negativas aos "outros sujeitos" representam a instalação de um conflito político, com o objetivo de manter e até reforçar as representações negativas, assim como os lugares atribuídos a eles. Assim sendo, "[...] as formas de pensar e alocar o povo, os trabaIhadores, foram produzidas nesse entrelaçado de relações sociais, políticas de dominação/subordinação entre classes, etnias, raças" (ARROYO, 2014, p. 123).

Por isso, a manutenção e o reforço de um éthos de desvalor no tocante às populações indígenas e negra compõem o mecanismo de que o pensamento social (neo)conservador faz uso para manter o status quo, além de inibir, frear ou controlar as lutas sociais por direitos das populações indígenas e negra, assim como naturalizar a questão racial, como se o racismo fosse inexistente. Com isso, torna-se imperativa a indagação de Arroyo (2014, p. 122) que reflete sobre o motivo pelo qual esses segmentos populacionais se tornaram um incômodo e provocam reações de controle: 


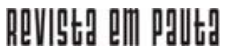

\} PROTAGONISMO NEGRO - MOCELIN, C. E.; GROSSI, P. K. \}

DOI: $10.12957 /$ REP.2020.52058

Porque se contrapõem a apropriação/expropriação da terra e do espaço, a exploração do trabalho e a destruição da agricultura camponesa, da produção de alimentos para a vida... A diversidade de lutas e de ações coletivas populares e de movimentos sociais mexem nas estruturas e relações mais brutais de dominação/subordinação dos trabalhadores, dos setores populares.

O autor diz que as lutas sociais por direitos os colocam "[...] nos núcleos estruturantes das relações políticas de dominação/subordinação. Da produção-reprodução das desigualdades" (ARROYO, 2014, p. 122). Nisso, a manutenção da ideologia e do éthos do não direito, ou melhor, da negação do direito à terra, ao trabalho, ao conhecimento, à educação, à cultura, perpetua-se na sociedade brasileira capitalista, patriarcal e racista, visando justificar a manutenção das desigualdades sociais, étnicas, raciais, geracionais, de gênero, do campo e regionais. São desigualdades que, sob um viés moral, ocultam a raiz estrutural da questão social a partir da lei geral de acumulação capitalista (MARX, 2013).

Portanto, são os sujeitos coletivos oprimidos pelos processos de colonização que questionam as políticas públicas, mas sobretudo resistem às segregações e exigem seus direitos, pois, no processo de formação social brasileira, esses Ihes foram negados. Dessa forma, há uma relação dialética e contraditória entre a reação política para com "os outros sujeitos" e a radicalidade política existente nesses "outros sujeitos" e nos seus movimentos de luta por direitos (ARROYO, 2014).

"Os outros sujeitos" foram construídos no imaginário social, mas também na concretude da vida, para serem sujeitos que estão posicionados na divisão social e técnica do trabalho, nas formas mais precarizadas de trabalho, recebendo salários inferiores. Além disso, residem em bairros segregados por processos de gentrificação e pela expulsão espaço-territorial do capital, configurando o que alguns autores chamam de racismo ambiental ${ }^{4}$. Vivem também atualmente uma demonização de seus credos, ritos e culturas.

A presença afirmativa desses que são considerados pela elite dominante como "os outros sujeitos" no âmbito das universidades mexe com o já instituído. Além disso, compreende-se que o acesso à educação ou o direito à educação como parte da riqueza socialmente produzida não se dá de forma equitativa entre as diversas classes sociais, em razão de que "Esta desigualdade, esta injusticia, - que no es sino un reflejo y una consecuencia, en el mundo de la enseñanza, de la desigualdad y de la injusticia que rigen en el mundo de la economía" (MARIÁTEGUI, 2003, p. 50).

\footnotetext{
${ }^{4} \mathrm{O}$ racismo ambiental constitui-se num tipo de desigualdade e injustiças socioambientais impostas às etnias e comunidades tradicionais em razão de empreendimentos do capital. Com isso, expelem tais populações de seus territórios, desorganizando suas culturas. Estas são empurradas para as favelas das periferias urbanas, convivendo forçosamente com a degradação de seus ambientes de vida (HERCULANO, 2008).
} 


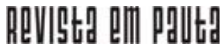

\} PROTAGONISMO NEGRO - MOCELIN, C. E.; GROSSI, P. K. \}

DOI: $10.12957 / R E P .2020 .52058$

Portanto, a escolaridade é um elemento característico da diferença entre as classes sociais que se soma ao elemento fundante da propriedade privada dos meios de produção. Ou seja, a educação no capital não é algo a priori destinado à classe trabalhadora. Contudo, quando a educação contempla "os outros sujeitos", impõem-se limites, tais como a permanência nos sistemas de ensino, em razão de que "La enseñanza, en el régimen demo-burgués, se caracteriza, sobre todo, como uma enseñanza de clase. La escuela burguesa distingue y separa a los niños en dos clases diferentes" (MARIÁTEGUI, 2003, p. 49-50).

Vê-se, assim, que as instituições de educação formal sempre possuíram seu recorte de classe e raça, estando alinhadas aos interesses das classes dominantes e tendo como objetivo fundamental a reprodução dos valores, ideologias e do éthos burguês. Dessa forma, a escola opera como reprodutora na manutenção das classes e desigualdades raciais, sendo que o capitalismo e o racismo interagem entre si formando um nó indissociável nesse modo de produção. É nesse sentido que a escola por si só não modificará o mundo, como os jargões (neo)liberais do reformismo pedagógico alardeiam. O mundo transforma-se e, com ele, a escola. Todavia, os processos educativos podem potencializar, ainda que sob os limites do capital, práxis antirracistas, considerando o protagonismo dos ditos "outros sujeitos". O próximo item se propõe a tensionar tal perspectiva.

\section{O protagonismo negro como pressuposto para uma educação antirracismo}

Tomar como pressuposto a necessidade de ressignificar o que outrora fora aprendido por meio das relações familiares, comunitárias e educacionais no que tange às relações raciais é apostar na educação e na cultura como alternativas e estratégias de que a sociedade dispõe para a promoção e construção de relações sociais democráticas, equitativas e antirracistas, pois

A escola tem papel preponderante para eliminação das discriminações e para emancipação dos grupos discriminados, ao proporcionar acesso aos conhecimentos científicos, a registros culturais diferenciados, à conquista de racionalidade que rege as relações sociais e raciais, a conhecimentos avançados, indispensáveis para consolidação e concerto das nações como espaços democráticos e igualitários. (BRASIL, 2004, p. 15).

Por isso, as escolas e as universidades não podem continuar a lateralizar a questão racial e relegar a sua parca discussão a determinadas datas, como o Dia da Consciência Negra e/ou da Abolição da Escravatura. A transversalidade da discussão da questão racial deve fazer-se presente 


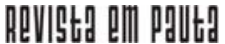

\} PROTAGONISMO NEGRO - MOCELIN, C. E.; GROSSI, P. K. \}

DOI: $10.12957 /$ REP.2020.52058

nas ações realizadas continuamente durante o ano, e não em momentos delimitados, como aponta a fala da quilombola:

A [...] mesmo, a do posto [de saúde] lá, fez um grupo, conseguiu juntar um grupo de jovens e tá trazendo assim, resgatando bastante coisas tanto de costume dos nossos antigos, da nossa vó e quanto à história, à memória mesmo da comunidade. Então tá bem. Agora mesmo começa principalmente o mês de novembro, que é pra ser o ano todo, não precisava ser só em novembro pra se discutir questão racial, a questão do negro e da escravidão. (Quilombo Alpes - Grifo nosso).

Além disso, tais práticas antirracistas não podem restringir-se ao âmbito dos espaços educativos. Devem espraiar-se para serviços de assistência social, serviços de saúde (como na fala acima), sistema prisional e demais instituições públicas e privadas nas quais os/as assistentes sociais inserem-se em processos de trabalho coletivos enquanto trabalhadores/as especializados/as e, assim, defendem e materializam o projeto ético-político profissional.

As condutas racistas não nascem exclusivamente nos contextos educacionais, ainda que neles possam ser reproduzidas, pois estas são atravessadas pelas relações sociais constitutivas do modo de produção capitalista. Contudo, essas instituições não devem ficar omissas frente a tais opressões, expressas por meio de piadas e bullying entre os/as estudantes, o chamado racismo recreativo ${ }^{5}$ (MOREIRA, 2018).

Nessa perspectiva, o combate ao racismo, às discriminações e a construção de novas relações étnico-raciais não são tarefas específicas das instituições educacionais. Todavia, frequentemente seus currículos não contemplam a história e a cultura africana, afro-brasileira e indígena consoante às Diretrizes Curriculares Nacionais para a Educação das Relações ÉtnicoRaciais e para a educação escolar quilombola, corroborando a perpetuação do racismo institucional ${ }^{6}$ (ALMEIDA, 2018). No relato da integrante do Quilombo Urbano do Areal, observamos a manutenção do apagamento dos "outros sujeitos de direito" nas escolas, contribuindo para uma educação segregadora. O protagonismo negro é, assim, pressuposto e condição sine qua non para uma educação antirracismo, em que a população quilombola demanda:

Que entrasse essa discussão do negro, porque do índio parece que já estudam, até porque eles que são os donos da terra, eles que são os verdadeiros donos do Brasil, nem nós negros que somos. Eles que

\footnotetext{
${ }^{5} \mathrm{O}$ racismo recreativo utiliza o humor para propagar o preconceito racial, reproduzindo estigmas sociais que legitimam uma estrutura social discriminatória e hostilizando essas minorias (MOREIRA, 2018).

${ }^{6} \mathrm{Na}$ concepção de Almeida (2018), o racismo institucional define que os conflitos raciais também são parte das instituições. Sendo assim, o racismo não se reproduz apenas individualmente, mas também por meio das instituições, que em seu funcionamento reproduzem vantagens e privilégios a partir da raça.
} 
são. Botasse o estudo pelo menos para que todos nós conscientizássemos. Até porque acho que tem muito professor que não sabe, então passa pros alunos, apenas aquilo que eles sabem. O que eu aprendi sobre África, eu aprendi no computador, eu nem sabia sobre os reis que tinham, do ouro, do dinheiro e que muita coisa foi aprendida com o povo africano. (Quilombo Areal - Grifo nosso).

Diante disso, o enfrentamento do racismo exige o debate de ideias, a ressignificação de conceitos e, sobretudo, uma educação que priorize, fomente e construa novas relações étnico-raciais. Isso porque é fato que o racialismo ${ }^{7}$ e as teorias deterministas fazem-se presentes no imaginário e nas ações concretas de indivíduos, com o propósito de desqualificar e inferiorizar pessoas em razão da cor da pele, principalmente na atual conjuntura. Por isso, as Diretrizes para a Educação das Relações Étnico-Raciais apontam que, "Para obter êxito, a escola e seus professores não podem improvisar. Têm que desfazer mentalidade racista e discriminadora secular, superando o etnocentrismo europeu, reestruturando relações étnico-raciais e sociais, desalienando processos pedagógicos" (BRASIL, 2004, p. 15).

Em outro movimento, além do apagamento da população negra nos e dos espaços educacionais por meio de reiterados processos de racismo institucional (ALMEIDA, 2018), a fala quilombola demarca o reducionismo operado pela escola na questão da religião diante do conjunto da cultura, condições e modos de vida desta população, tendo em vista que a escola:

Não, não traz nada não. Nada, nada, nada, só religião, só a religião. Porque os professores não se interessam nem em mandar um tema, uma coisa assim. Só falam de negro quando foi escravizado, não falam que o negro ajudou na lavoura, ajudou a levantar o Brasil, cuidou filho de branco. A gente aprende essas coisas na escola de samba. Tu pode só pegar as escolas de samba do Rio e ver os temas que estão desfilando, não é aleatório. Cada tema desse é pensado e contado a história tintim por tintim. (Quilombo Areal - Grifo nosso).

A partir desse relato, podemos destacar a importância dos espaços de educação popular, como as escolas de samba, nos quais se processam práxis educacionais conduzidas por uma perspectiva afirmativa e emancipatória. O Quilombo Alpes, por sua vez, está construindo parcerias com as escolas próximas ao território quilombola, trazendo para as salas de aula a mediação com a cultura negra, o que, na avaliação da mulher quilombola, tem sido:

Sim, sim, sim, bem atuante, sim. Tanto uma escola como a outra. Inclusive, como já disse, já teve trocas, da gente tá indo lá, tá levando um pouco do histórico. E eles têm todo um trabalho lá de resgate, de

\footnotetext{
${ }^{7}$ Conjunto das ciências que busca comprovar que a raça humana está subdividida em outras raças e sub-raças, baseando-se em autores como Joseph de Gobineau, João Batista de Lacerda, Silvio Romero e Nina Rodrigues.
} 


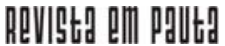

\} PROTAGONISMO NEGRO - MOCELIN, C. E.; GROSSI, P. K. \}

DOI: $10.12957 /$ REP.2020.52058

capoeira, de rap, de várias coisas, assim, bem legal o trabalho que fazem com as crianças lá. Tanto numa escola como na outra. (Quilombo Alpes - Grifo nosso).

A mudança de paradigma na forma de pensar e ressignificar o lugar atribuído à população negra passa inevitavelmente pela educação, pois esta permite que "[...] pedagogias de combate ao racismo e a discriminações elaboradas com o objetivo de educação das relações étnico/raciais positivas" (BRASIL, 2004, p. 16) fortaleçam as/os negras/os e, ao mesmo tempo, despertem entre os/as brancos/as a consciência negra. Além disso, a utilização de recursos tecnológicos pode ser potencializadora para a democratização e socialização de informações na perspectiva de acesso e garantia de direitos, como aponta a mulher quilombola no trecho a seguir:

Eu vi no computador eles podiam passar para escola e estudar essas coisas, os nossos índios também. Só se falam dos alemães, dos italianos, um pouco dos japoneses que também não é muito. Principalmente aqui no Sul que é as colônias italianas e alemães e nada do negro. Eles fizeram muitas coisas, mas até eles chegarem aqui quem é que fez tudo isso... Foi o braço negro que fez. E o que a princesa Isabel... será que não é como no samba diz?! Que a tão sonhada e esperada liberdade não é pura ilusão? Saímos da chibata e fomos para a favela. Esse samba da Mangueira é muito interessante. (Quilombo Areal - Grifo nosso).

A fala acima aduz para a tomada de consciência acerca da importância e contribuição do trabalho da população negra na construção e manutenção do Brasil, indo de encontro à perspectiva eurocêntrica, muito valorizada nos estados do sul do país, na qual a etnia alemã e italiana é vista como trabalhadora. Manifesta também a perpetuação, desde a escravidão até os processos de segregação socioespacial e opressão socioeducacional, que mantém as hierarquias de desigualdades sociais no âmbito do capitalismo, razão pela qual desde o século XIX o estigma, o preconceito e o desvalor da população negra vêm sendo construídos, contribuindo para a naturalização do racismo existente. Em consequência, a sociedade brasileira, a partir de discursos, representações midiáticas e processos socioeducativos, aprendeu a ver e definir a população negra sempre em posições subalternizadas.

Por isso, a maioria dos/as estudantes universitários, brancos/as, estão acostumados/as a ver pessoas brancas em posições de prestígio e muitos/as naturalizam as relações sociorraciais desiguais e perversas. Ao passo que ver a população negra tomando consciência e vislumbrando novas oportunidades de mobilidade social causa um certo estranhamento e desconforto, pois tal cenário é visto como "antinatural", subvertendo o status quo. 


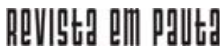

\} PROTAGONISMO NEGRO - MOCELIN, C. E.; GROSSI, P. K. \}

DOI: $10.12957 / R E P .2020 .52058$

Ademais, cumpre destacar que a população negra foi impedida de acessar os bancos escolares. No período escravocrata, foi por determinação legal. Atualmente, a discriminação sociorracial, a violência e o racismo contribuem para o não acesso ou para a retenção e/ou abandono escolar. É o que aponta a quilombola ao dizer que "a gente já tá com uma dificuldade de manter eles na escola. Agora mesmo os jovens aí, a gente conseguiu esse ano pegar uns 10 jovens aqui da comunidade e conseguiu ir fazer eles concluírem os estudos, que eles tinham parado" (Quilombo Alpes - Grifo nosso). Diante disso, as políticas públicas de permanência escolar devem ser fortalecidas, haja vista as condições socioeconômicas ${ }^{8}$ desta população, pois o capitalismo se utiliza do racismo para se reproduzir e para ocultar as condições de dominação e exploração racial, criando justificativas no sentido de naturalizar e normalizar quaisquer situações de discriminação racial.

Em relação à educação quilombola, urge a necessidade de ações inovadoras que garantam a formação inicial e continuada dos professores, projeto político-pedagógico que considere as especificidades dos/das quilombolas, currículo diferenciado, material didático produzido em conjunto com a comunidade, educação voltada ao etnodesenvolvimento e para o desenvolvimento sustentável e efetivação de professores oriundos do referido grupo social (FIABANI, 2013).

De acordo com Francisco Jr. (2008), a discussão e problematização da questão racial também deve ocorrer nas escolas, pois esta tornase um poderoso instrumento na prática educativa antirracista. O autor elenca alguns elementos necessários em uma educação antirracista: o reconhecimento da questão racial na sociedade brasileira; a reflexão permanente sobre o racismo na escola e na sociedade; recusa a qualquer manifestação ou prática de preconceito ou discriminação; respeito à diversidade presente no cotidiano escolar; construção de currículos menos eurocêntricos e valorização da contribuição dos diferentes grupos na construção do nosso país, a fim de contribuir para o reconhecimento, fortalecimento e autoestima da identidade racial de educandos/as pertencentes a grupos discriminados.

\section{Considerações finais}

A perspectiva da construção de uma educação antirracismo como um processo de luta social não pode se restringir apenas ao reconhecimento dessas populações. É necessário pensar e tomar a educação como processos sociais e práticas afirmativas e antirracismos acerca das populações que

\footnotetext{
${ }^{8}$ Segundo a V Pesquisa (2019), os/as estudantes de etnia branca possuem como renda média mensal familiar per capita a cifra de $\mathrm{R} \$ 1.720,00$, enquanto que para os/as pardos/as esse valor é de $\mathrm{R} \$ 1.033,00$. Para estudantes pretas/ os não quilombolas, a renda é de R\$912,00 (aproximadamente 47\% de defasagem), enquanto que para as/os pretas/ os quilombolas é de R\$ 625,00 (aproximadamente $64 \%$ de defasagem).
} 


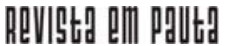

\} PROTAGONISMO NEGRO - MOCELIN, C. E.; GROSSI, P. K. \}

DOI: $10.12957 /$ REP.2020.52058

foram historicamente ocultadas, segregadas e oprimidas em sua cultura, seu modo de vida e, sobretudo, como sujeito sem direito a ter direitos. Vêse, assim, uma dialética entre afirmação da população negra e quilombola, ainda vista muitas vezes como "outros sujeitos", visão que contribui para a repressão e manutenção das formas de dominação e desigualdades étnico raciais.

Persiste a necessidade de aprofundar as discussões sobre a formação social do país e, principalmente, despertar a consciência na população branca de que a raça opera como um limitador de ascensão e mobilidade social, restringindo muitas e diferentes oportunidades de vida para a população negra. Nesse sentido, adotar o critério racial, atualmente, no Brasil, é compreender que as desigualdades socioeconômicas, aqui, são também raciais. A pobreza, a violência, o analfabetismo, o juvenicídio e o feminicídio têm cor, gênero e lugar.

Ao longo da história, o movimento antirracista tem denunciado as desigualdades raciais no bojo da sociedade capitalista. A perspectiva de totalidade nos leva ao imperativo de colocar no centro da discussão acadêmica as questões da raça, classe e gênero como indissociáveis, pois dentro da estratificação social as mulheres negras constituem a base dessa pirâmide. A visão de "não sujeitos" deve ser transmutada para a visão de sujeitos de direitos, não mais centrada numa discussão periférica e sim central.

Reafirmamos a importância de uma educação antirracismo em todos os espaços, desde a família até a mídia, a igreja, a escola, nos partidos políticos, no sistema de justiça e segurança pública. Uma educação que desafie e questione os parâmetros vigentes, que estabelecem a branquitude como norma e os demais como os "outros", "os diferentes", "os perigosos", "os incivilizados", entre outros atributos que reforçam a subalternidade na sociedade. Afirmar a negritude implica a luta para a superação de uma herança escravocrata da nossa sociedade na perspectiva de construção de novos padrões de sociabilidade. Formar uma consciência racial é a primeira etapa, o que passa pela valorização da negritude, da cultura afro e da tradição. Pressupõe mostrar a história de um povo com o olhar do povo negro, e não com o olhar do colonizador. Como diria Marx (2013), trazer à tona a história dos vencidos é urgente e necessário. Portanto, a luta antirracista deve vir sempre acompanhada da luta anticapitalista, antipatriarcalista e anticolonialista. 


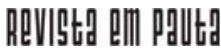

\} PROTAGONISMO NEGRO - MOCELIN, C. E.; GROSSI, P. K. \}

DOI: $10.12957 / R E P .2020 .52058$

\section{Referências}

ALMEIDA, S. L. O que é racismo estrutural? Belo Horizonte: Letramento, 2018.

ARROYO, M. G. Outros sujeitos, outras pedagogias. Petrópolis: Vozes, 2014. BRASIL. Decreto n. 1.331, de 17 de fevereiro de 1854. Approva o Regulamento para a reforma do ensino primario e secundario do Municipio da Côrte. Coleção de Leis do Império do Brasil, v. 1, 1854.

BRASIL. Decreto n. 7.031-A, de 6 de setembro de 1878. Crêa cursos nocturnos para adultos nas escolas publicas de instrucção primaria do $1^{\circ}$ gráo do sexo masculino do municipio da Côrte. Coleção de Leis do Império do Brasil, v. 1, 1878.

BRASIL. Decreto n. 4.228, de 13 de maio de 2002. Institui, no âmbito da Administração Pública Federal, o Programa Nacional de Ações Afirmativas e dá outras providências. Diário Oficial da União, 14 maio 2002.

BRASIL. Decreto Presidencial n. 4.887, de 20 de novembro de 2003. Regulamenta o procedimento para identificação, reconhecimento, delimitação, demarcação e titulação das terras ocupadas por remanescentes das comunidades dos quilombos de que trata o art. 68 do Ato das Disposições Constitucionais Transitórias. Diário Oficial da União, 21 nov. 2003a.

BRASIL. Lei n. 10.639, de 9 de janeiro de 2003. Altera a Lei no 9.394, de 20 de dezembro de 1996, que estabelece as diretrizes e bases da educação nacional, para incluir no currículo oficial da Rede de Ensino a obrigatoriedade da temática "História e Cultura Afro-Brasileira", e dá outras providências. Dário Oficial da União, 10 jan. 2003b.

BRASIL. Diretrizes curriculares nacionais para a educação das relações étnico-raciais e para o ensino de história e cultura afro-brasileira e africana. Brasília: MEC, 2004. Disponível em: http://www.uel.br/projetos/leafro/pages/ arquivos/DCN-s\%20-\%20Educacao $\% 20$ das\%20Relacoes\%20EtnicoRaciais.pdf. Acesso em: 21 maio 2019.

BRASIL. Lei n. 12.711, de 29 de agosto de 2012. Dispõe sobre o ingresso nas universidades federais e nas instituições federais de ensino técnico de nível médio e dá outras providências. Diário Oficial da União, 30 ago. 2012.

CFESS. Código de Ética do/a assistente social. Lei n. 8.662/93 de regulamentação da profissão. Brasília: CFESS, 2012.

EURICO, M. C. A percepção do assistente social acerca do racismo institucional. Serviço Social e Sociedade, São Paulo, n. 114, jun. 2013. 


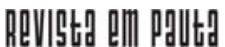

\} PROTAGONISMO NEGRO - MOCELIN, C. E.; GROSSI, P. K. \}

DOI: $10.12957 /$ REP.2020.52058

FIABANI, A. As diretrizes curriculares nacionais para a educação escolar quilombola: a necessária ruptura de paradigmas tradicionais. Identidade!, v. 18, n. 3, dez. 2013.

FRANCISCO JR., W. E. Educação anti-racista: reflexões e contribuições possíveis do ensino de ciências e de alguns pensadores. Ciência e Educação, v. 14, n. 3, 2008.

FUNDAÇÃO PALMARES. Certificação Quilombola. Comunidades Remanescentes de Quilombos (CRQs). 2020. Disponível em: http://www. palmares.gov.br/wp-content/uploads/2015/07/TABELA-DE-CRQCOMPLETA-QUADRO-GERAL-3.pdf. Acesso em: 25 jun. 2020.

HERCULANO, S. O clamor por justiça ambiental e contra o racismo ambiental. Revista InterfacEHS, v. 3, n. 1, jan./ abr. 2008.

IAMAMOTO, M. V. O Serviço Social em tempo de capital fetiche: capital financeiro, trabalho e questão social. São Paulo: Cortez, 2015.

MARIÁTEGUI, J. C. Temas de educación. Lima, Peru: Amauta, 2003.

MARIÁTEGUI, J. C. 7 ensayos de interpretación de la realidade peruana. Venezuela: Fundación Biblioteca Ayacucho, 2007.

MARX, K. O capital: crítica da economia política. São Paulo: Boitempo, 2013.

MOREIRA, A. O que é racismo recreativo? Belo Horizonte: Letramento, 2018.

SILVA, W. H. O mito da democracia racial: um debate marxista sobre raça, classe e identidade. São Paulo: Sundermann, 2016.

$\checkmark$ PESQUISA do perfil socioeconômico e cultural dos estudantes de graduação 2018. Uberlândia: Fonaprace, 2019. Disponível em: http:// www.andifes.org.br/wp-content/uploads/2019/05/V-Pesquisa-do-PerfilSocioecon\%C3\%B4mico-dos-Estudantes-de-Gradua\%C3\%A7\%C3\%A3odas-Universidades-Federais-1.pdf. Acesso em: 1 jul. 2019.

DOI: 10.12957/rep.2020.52058

Recebido em 21 de julho de 2019.

Aprovado para publicação em 20 de maio de 2020.

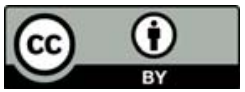

A Revista Em Pauta: Teoria Social e Realidade Contemporânea está licenciada com uma Licença Creative Commons Atribuição 4.0 Internacional. 